\title{
APROXIMACIÓN A LA GESTIÓN TERRITORIAL RURAL DESDE UN MODELO DE ORDENAMIENTO AGROAMBIENTAL
}

\section{APPROACH TO THE RURAL LAND MANAGEMENT, FROM A MODEL OF AGRI-ENVIRONMENTAL PLANNING}

\author{
Adriana Posada Arrubla ${ }^{1}$, Hanner Yesid Ramírez Poveda ${ }^{2}$ \\ ${ }^{1}$ Economista Agrícola, Esp. Gestión Social y Ambiental, M.Sc. Planeación Urbana y Regional, Docente Facultad Ingenierías. \\ Universidad de Ciencias Aplicadas y Ambientales U.D.C.A, calle 222 \#55-37, Bogotá, D.C., Colombia, e-mail: aposada@ \\ udca.edu.co; ${ }^{2}$ Líder Comunitario Bajo Sumapaz, Joven investigador U.D.C.A, Ingeniero Geógrafo y Ambiental. Universidad \\ de Ciencias Aplicadas y Ambientales U.D.C.A, calle 222 No.55-37, Bogotá, D.C., Colombia, e-mail: haramirez@udca.edu.co
}

Rev. U.D.C.A Act. \& Div. Cient. 18(2): 513-523, Julio-Diciembre, 2015

\section{RESUMEN}

En Colombia aún existe un importante potencial en las comunidades rurales para gestar, desde su territorio, modelos de ordenamiento agroambiental, que permitan lograr un desarrollo sostenible, no sólo a escala local sino regional. Es el caso del territorio rural de Usme, en Bogotá, que se destaca por su riqueza ambiental, pero que requiere apoyos, de diversa índole, para hacer posible el mejoramiento de la calidad de vida del campesinado. Asunto que se puede potenciar con el diseño cartográfico a escala supramunicipal de un modelo, como el que se presenta, utilizando las bases del ordenamiento ambiental.

Palabras clave: Gestión ambiental, ordenamiento territorial, desarrollo rural, modelo rural.

\section{SUMMARY}

In Colombia there is still a significant potential within rural communities to gestate from their territory models of agrienvironmental systems that allow to achieve sustainable development, not only at the local, but also the regional level. This is the case of the rural territory of Usme in Bogota, which stands out for its environmental wealth, but which requires support of various kinds to make the improvement of the quality of life of the habitants possible. Issue that can be enhanced with the cartographic design at supra-municipal level of a model as it is presented here, using the bases of environmental system management.

Key words: Environmental management, land management, rural development, rural model.

\section{INTRODUCCIÓN}

La capital de Colombia cuenta con una gran extensión rural, pero las políticas sucesivas de favorecimiento al desarrollo urbano han traído consecuencias que ocasionan desequilibrios para el campesinado. Los conflictos por el uso actual y potencial del territorio, impactan la estructura ambiental y social de las ruralidades. Las nuevas dinámicas urbano-rurales exigen prever los conflictos territoriales, considerando los intereses intrínsecos de quienes por años, han sentido, como parte de su deber ser, el hacer posible un desarrollo sostenible (Posada, 2009). Es un desafío mundial, la preservación de los recursos naturales y agrícolas y la integración de los productores a los mercados nacionales o globales, al tiempo que se les brinde mejores oportunidades, herramientas y facilidades (Ayala Ortiz et al. 2008). En esa misma vía, Carvajal Sánchez (2011) plantea la necesidad de rescatar una política en la que se construya el territorio, a través de la reivindicación identitaria o la exigencia de derechos por parte de los actores sociales.

En Colombia, la mayoría de las experiencias de tipo agroambiental, promovidas por la política pública, incorporan uno o varios criterios agroambientales, ligados a prácticas de menor impacto, sin que su actividad pase a ser de tipo alternativo o sostenible (Bustamante, 2013). Para Garay Salamanca et al. (2013) resulta necesaria y conveniente la adopción de un modelo de desarrollo rural con enfoque territorial, que propenda por una progresiva inclusión social y un reconocimiento del campesinado como agente social, productivo y político, para la transformación de la ruralidad en Colombia. Según Bustamante (2013), en el país no existe una política agroambiental explicita; sin embargo, se han incorporado 
elementos legislativos de tipo ambiental al quehacer agropecuario. Lo que ha existido son iniciativas sectoriales o intersectoriales que promueven sistemas o prácticas agrarias, para el mejoramiento de las relaciones producción agrariaconservación ambiental, las cuales, surten una serie de procesos hacia la formulación e implementación de planes, de programas o de proyectos.

Para Posada (2014), no es suficiente con una serie de planes, se requiere un impulso más para la verdadera acción. Este impulso, se puede dar en la construcción colectiva del modelo de ordenamiento que la comunidad desea, en este caso, el modelo de OAA, pero según Mera Chará \& Galindo Lucas (2005), diversos modelos de desarrollo propugnan la consecución de una sociedad próspera y civilizada, como consecuencia lógica de una base de recursos naturales, abundantes y variados, asunto que en Colombia se exceptúa como consecuencia de factores externos, como la demanda de productos agrícolas. La FAO (2014), por su parte, sostiene que el ejercicio de la planificación en el sector agroambiental es fundamental, ya que a través de la planificación, se definen también las responsabilidades relativas a la conducción y la operación de las medidas agroambientales.

Aquí encajan los principios de ordenamiento agroambiental, los cuales, según Mateus Moreno \& Rojas Salazar (2013), son una herramienta de planeación, que concreta los proyectos de ordenación y de manejo del territorio, desde un enfoque comunitario y se complementa con el criterio de Sepúlveda et al. (2003), para quienes la complejidad de la estructura económica de un territorio rural, supera con creces el concepto de agricultura ampliada y de cadenas agroalimentarias, que amerita un enfoque territorial holístico. Ejercicios comparativos, como el realizado por la Universidad del Rosario (2012), demuestran que para lograr un desarrollo económico es imprescindible respetar, como soporte regional, a la base natural ambiental, que propicia la disponibilidad hídrica, lo que se convierte, a su vez, en una estrategia que posiciona a los territorios en un escalafón de competitividad integral.

Aproximarse a la gestión territorial rural, desde un modelo de ordenamiento agroambiental, en adelante OAA, es una invitación que se hace a través de este escrito, recreando esta idea, en el caso específico de la ruralidad de UsmeBogotá, donde el deterioro ambiental se agudiza, debido a la inadecuada planificación de actividades agropecuarias, a la presión urbana sobre los ecosistemas regionales allí existentes, que hacen parte de la estructura ecológica principal y a la falta de una concreción en la acción colectiva, lo cual, se suma al llamado de Torres Lima et al. (2011), por una convergencia entre la evaluación de riesgos climáticos locales, la vulnerabilidad de sistemas agrícolas y las capacidades adaptativas de las poblaciones.

\section{MATERIALES Y MÉTODO}

El páramo de Sumapaz es un referente ambiental en Colombia, ya que en él se originan cinco cuencas de alta importancia, a nivel regional: río Tunjuelo, río Blanco, río Ariari, río Meta y río Sumpaz. En lo que respecta al distrito capital existe un fuerte compromiso, dado que en este páramo coexisten varias unidades de manejo territorial: desde la óptica administrativa, las localidades \#5 de Usme, \#19 de Ciudad Bolívar y \#20 de Sumapaz; desde lo ambiental, la zona rural de Usme y desde el enfoque social, la denominada zona del bajo Sumapaz, ubicada en las áreas rurales de la localidad de Usme, de Cuidad Bolívar y parte de la localidad de Sumapaz, además de tener territorio en los municipios de Soacha, de Sibaté Pasca, de Une, de Chipaque y parte de Gutiérrez, Cundinamarca.

El área rural de Usme, se caracteriza por ser un territorio de alta montaña y sus dinámicas son propias de la economía campesina de cultura cundiboyacense; sus pobladores, alrededor de 6.400 campesinos, tienen una relación directa con el páramo del Sumapaz y los afluentes del río Tunjuelo, a lo largo de sus 14 veredas (Mapa 1): Los Soches, El Uval, La Requilina, Corinto Cerro Redondo, Chiguaza, Olarte, El Destino, Curubital, Los Arrayanes, El Hato, Los Andes, Las Margaritas, La Unión y Chizacá. Con representantes de estas veredas, se llevaron a cabo tres talleres, para determinar cuál sería el modelo propuesto por las comunidades, que les permitiera hacer de su territorio una zona rural sostenible (Mapas 1 y 2).

En el mapa 2, se evidencia la importancia del sistema hídrico, que está compuesto por una importante cantidad de cuerpos de agua, tales como lagunas, embalses, ríos, quebradas y riachuelos, que pertenecen a la cuenca del río Tunjuelo y que, a su vez, abastecen a los embalses regionales de Chizacá y La Regadera. Los ríos más representativos de este sistema son Chizaca (nace en la laguna Los Tunjos o Chizacá, desciende hacia el norte pasando por las veredas de Chizacá, Las Margaritas y La Unión, hasta llegar al embalse de Chizacá), El Mugroso (nace en la laguna de Las Garzas, desciende por la vereda La Unión, hasta llegar al embalse de Chizacá) y El Curubital (nace en el páramo de Bocagrande, atraviesa las veredas de Curubital y Los Arrayanes, hasta llegar al embalse La Regadera, siendo su principal afluente).

La metodología dependió, en gran medida, del trabajo conjunto con la comunidad, con quienes se desarrolló cartografía social, para plasmar en mapas sus deseos sobre el futuro, desde la ruralidad de Usme, trascendiendo a la cuenca del río Tunjuelo y proyectándose hasta el ecosistema páramo. De ahí, que varias de las decisiones sobre las especificidades del modelo de OAA, se expliquen desde un deseo de la comunidad rural, a partir de sus conocimientos, que son 


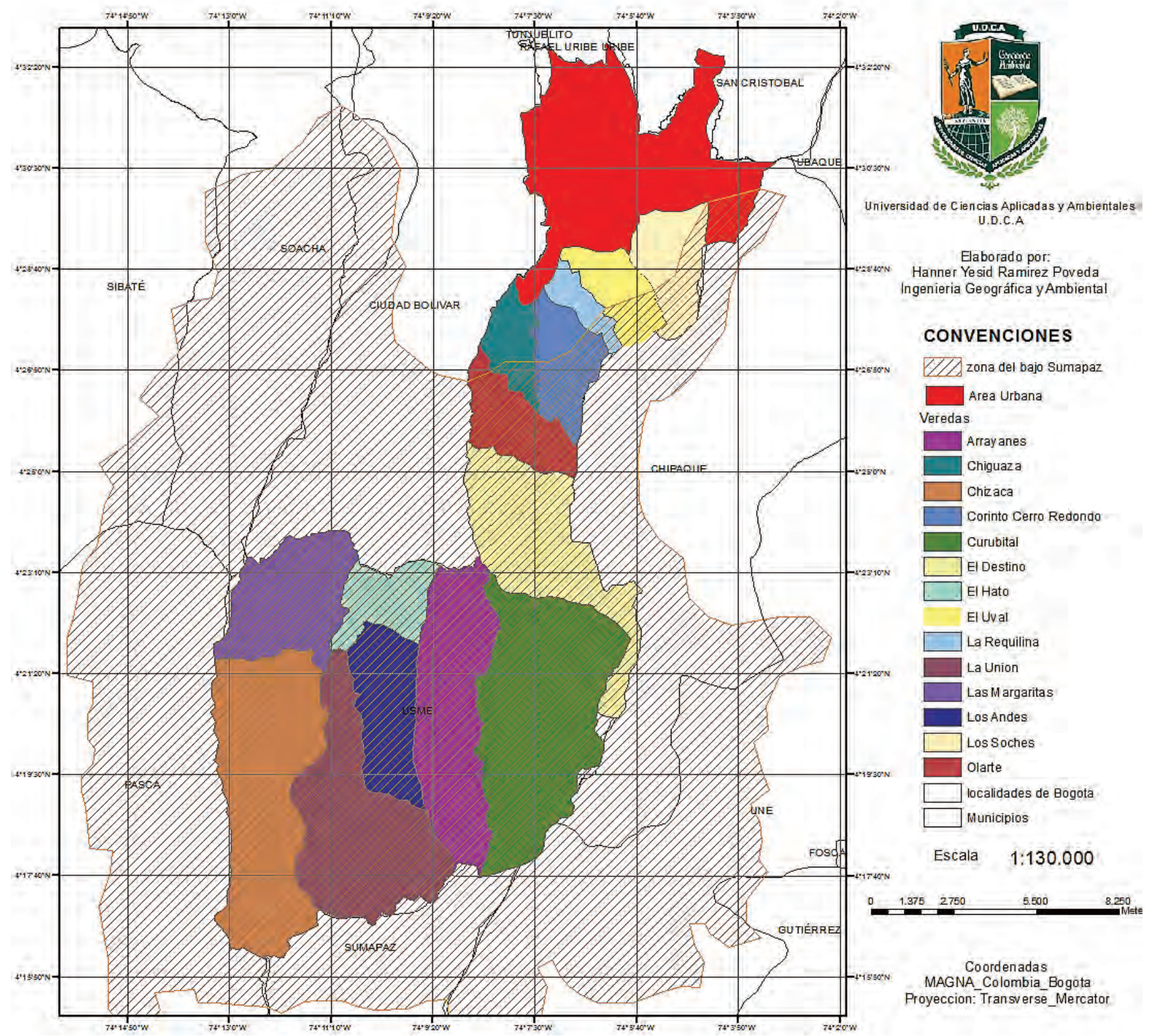

Mapa 1. Representación de la célula viva de la gestión territorial para el OAA: la vereda. 


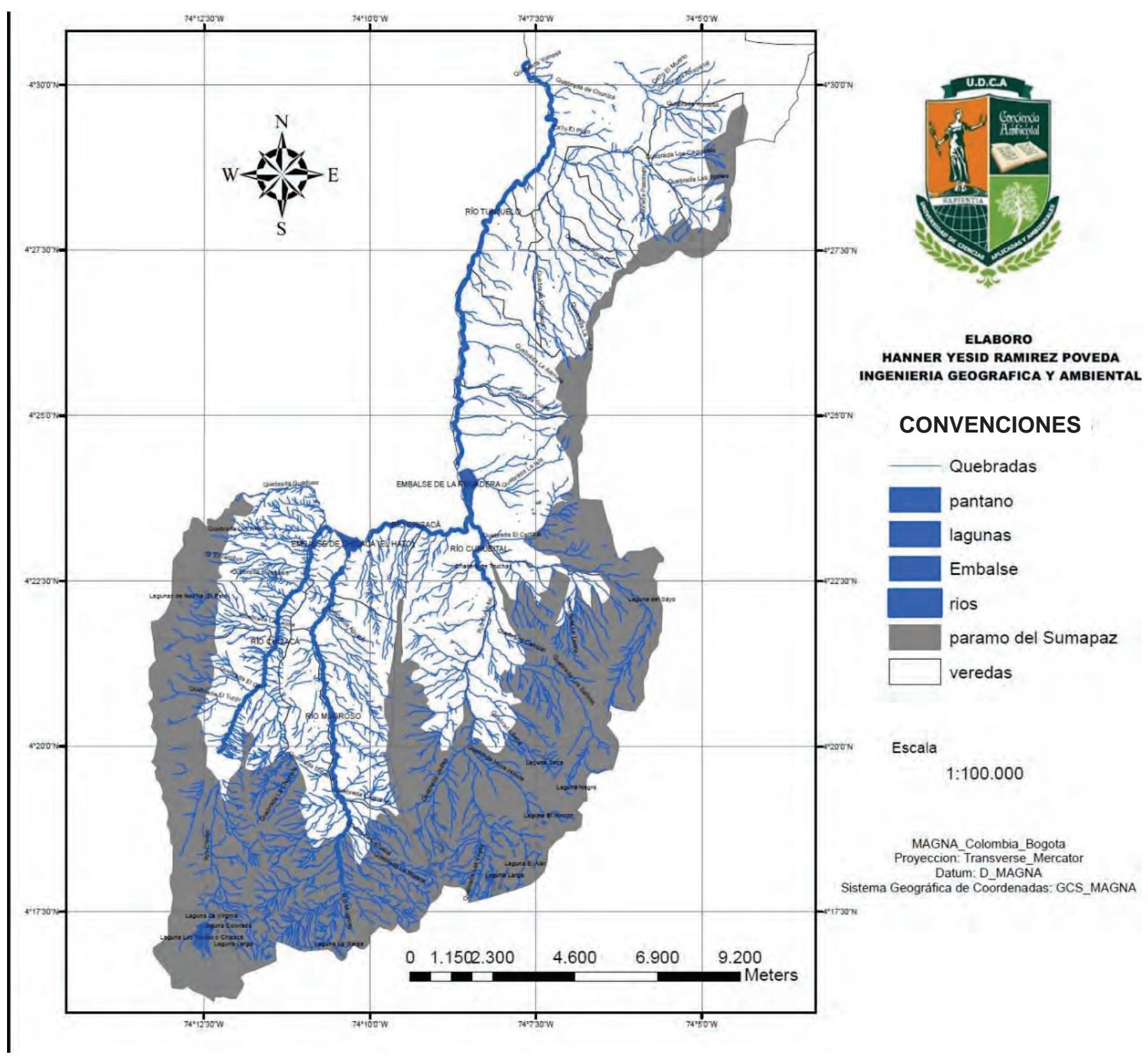

Mapa 2. Sistema hídrico zona rural de Usme, 2015. 
derivados de la cotidianidad, en el contacto con su territorio. Para el diseño cartográfico, se trabajó con el software ARC GIS 10.2.1, como técnica de mapeo, que permite integrar las iniciativas descritas por los campesinos. También, se emplearon imágenes satelitales, proporcionadas por google earth, realizando la fotointerpretación, para conocer el área que ocupan los principales elementos, que componen el modelo OAA.

Para diseñar el modelo cartográfico, se estableció, como eje central, al río Tunjuelo y, como nodo, al ecosistema del páramo Sumapaz; luego, se procedió a superponer las distintas capas temáticas necesarias, como el límite de predios, la hidrografía, las vías, el centro poblado rural, cuya base de datos se encuentra en la Alcaldía Distrital de Bogotá. Posteriormente, se ubicaron los corredores biológicos en las zonas de rondas hídricas; luego, se insertaron las cercas vivas propuestas por la comunidad en cada uno de los límites prediales. Es importante expresar que para determinar la zona de páramo, se realizó una fotointerpretación adicional, ya que los entes encargados de definir el área de este ecosistema no manejan los mismos parámetros, es decir, la Corporación Autónoma Regional, establece como zona de páramo aquella mayor a la cota de los 3.000 msnm y para el Instituto de Investigaciones Alexander Von Humboldt corresponde a la zona de amortiguamiento del parque nacional Sumapaz, entonces, en este trabajo, se realizó una superposición de mapas para combinar los atributos y establecer un perímetro, que conjugara al complejo páramo de Sumapaz y Cruz Verde.

A partir de este esquema y empleando la herramienta de buffer, que en el Arc Gis básico permite crear zonas de influencia específicas, se subdividió a la zona rural de Usme en tres subzonas agroambientales, con un radio de $5 \mathrm{~km}$ cada una, así: la zona aledaña al pueblo de Usme, la zona circundante del embalse La Regadera y la zona perimetral del embalse de Chizacá. Y aunque en la escala de la representación cartográfica del modelo OAA no es posible presentar un nivel de detalle, se quiere dar a conocer que, de acuerdo a las propuestas de la comunidad, se definieron componentes, tales como cercas vivas y corredores biológicos, principalmente y, para representar los buffer en el software ARC GIS10.2.1, se tomaron como valores, aquellos resultantes del promedio planteado por los campesinos, así: para el caso del límite predial, se manejó un buffer de cinco metros a lado y lado de los predios rurales; en las quebradas y los riachuelos, se manejó un buffer de ocho metros a lado y lado; en los nacederos, aljibes o reservorios de agua, se estableció un buffer de seis metros alrededor de ellos y para las vías o caminos, el buffer que se utilizó fue de cinco metros al lado y lado. El buffer manejado para los ríos es el exigido por la República de Colombia (1974), es decir, de 30m a lado y lado de su ronda hídrica, debido a que se considera un área de especial importancia ecológica de dominio público.

\section{RESULTADOS Y DISCUSIÓN}

La característica principal que diferencia un modelo de ordenamiento agrícola de un modelo agroambiental es que el territorio rural, objeto de la intervención, tiene una destacada connotación ambiental en el territorio natural sobre, el cual, se asienta la población que hará posible la gestión del modelo. Y si bien la gestión del territorio rural exige una posición sociocultural de sus pobladores muy asociada a la naturaleza, esta posición no sería posible si no existiese la condición natural precedente. Lugares como estos parecen no tener al conjunto de capitalinos a su favor, pero si se llegara a estudiar los intereses reales por mantener la sostenibilidad de este territorio, se encontraría un interesante porcentaje de personas que le apostarían por hacer posible su gestión territorial rural, como en el caso de la reserva forestal del norte de Bogotá, que alcanza a contar con un 15\% de interesados en ella (Posada, 2012). Por ello, se buscó representar la integración de aspectos agrícolas, pecuarios, ambientales y sociales, a través de un modelo OAA, para acercarse al tratamiento de la gestión territorial rural y, en particular, el modelo planteado, construido desde la comunidad, es un esfuerzo justamente por darle espacio a los pobladores de construir su futuro, desde la premisa producir conservando y conservar produciendo.

Para la ruralidad de Usme, esta prevalencia se demuestra a partir de los datos obtenidos con el análisis espacial, con el cual, se pudo evidenciar la distribución porcentual de la destinación del suelo y sus principales características estructurales y funcionales, destacando que el páramo, a pesar de haber perdido parte de su área original, continúa siendo el más representativo, con un 59\%, seguido del uso en ganadería, con un $22 \%$ y, posteriormente, en agricultura, con $19 \%$, asunto que denota máxima importancia, no solo desde la óptica de la demanda regional, sino, sobre todo, desde la oferta natural, que debe ser vista, no como una oportunidad más de explotación y usufructo exógeno, sino como la urgencia de apoyar adecuadamente a los campesinos, hacia una producción más limpia, que permita mantener el equilibrio de este territorio, para sí mismos y las futuras generaciones.

Una premisa de ésta propuesta es que el modelo de OOA se materializa desde los predios, como punto de partida, donde se evidencia la economía campesina al detalle, entonces, el predio representa al núcleo de la célula y la célula viva del OAA es la vereda, ya que en ella se involucran más actores, decisiones, interés y apuestas en común, representadas por las Juntas de Acción Comunal y por las organizaciones campesinas, ante las instancias decisorias del Distrito Capital, cuyo impacto de comunidad trasciende al área rural de la cuenca del río Tunjuelo y la zona del Bajo Sumapaz, hasta el páramo de Sumapaz. 
Con esta base, se diseñó el modelo de OAA, contemplando varias perspectivas (Cuadro 1): multitemporal, multiespacial (multiescalar) y multiobjetivo (multicriterio), cada una de las cuales, consideró la palabra de la comunidad campesina. Para trazar la perspectiva multitemporal, se definió, a partir de los elementos de la planificación territorial, un horizonte de tiempo de una década, en la que se establecen procesos y actividades graduales de gestión territorial rural, así: en el corto plazo, de uno a tres años; en el mediano, de cuatro a seis años y, en el largo plazo, de siete a diez años. En la perspectiva multiobjetivo, se contemplan distintos criterios, con un fin común, al buscar equidad en la optimización de la relación campesino-naturaleza: mejoramiento, implementación, fomento, impulso, consolidación, entre otros procesos, que permitirán el hacer, más que el prometer hacer. En cuanto a la perspectiva multiespacial, se definieron cuatro unidades agroambientales, partiendo desde la unidad privada predio; luego, se conjugan en la unidad central vereda; posteriormente, se potencian en una zona supraveredal y, al final, se consolida en la cuenca del río Tunjuelo, como la expresión espacial del sistema socioambiental predominante: el hídrico; por supuesto y como ya se ha explicado, todo ello dentro de la jerarquía estructural que permite el páramo de Sumapaz.

Con el fin de expresar con mayor detalle la forma espacial del modelo de OAA, se describe, como uno de los resultados, las siguientes tres subzonas agroambientales, que representan las principales dinámicas socioculturales del territorio de Usme, al interior de la cuenca del río Tunjuelo.

Zona agroambiental borde urbano-rural. Veredas con dinámicas rurales ligadas al área urbana de Bogotá: Los So- ches, El Uval, La Requilina, Chiguaza y Corinto Cerro Redondo, además, el pueblo de Usme. Se destaca una experiencia de defensa del territorio y una figura de gestión social, como lo es el Agroparque Los Soches, en donde los campesinos de 1.234 predios han promovido alternativas de desarrollo local, combinando el manejo de su ruralidad con las áreas protegidas.

Zona agroambiental La Regadera. Veredas con producción campesina a pequeña escala, en 953 predios, principalmente, dedicados al cultivo de papa, arveja y habas y a la ganadería: una parte de la vereda Olarte, El Destino, Curubital y Arrayanes; en esta zona, se encuentra el único centro poblado rural de Usme, El Destino, en donde la población rural de Usme y de algunas veredas aledañas de la localidad de Cuidad Bolívar y del municipio de Chipaque, obtiene servicios educativos y de salud.

Zona agroambiental El Hato. Es la zona más grande y es la que comprende mayor área del ecosistema páramo y en el área cultivable, se produce solamente papa; corresponde a 806 predios de las veredas El Hato, Las Margaritas, Los Andes, La Unión y Chizacá, en donde se ubica el nacimiento del río Tunjuelo.

\section{Diseño del modelo de ordenamiento agroambiental}

Es el producto de la superposición de varias capas temáticas, que fueron discutidas en los talleres comunitarios y en las entrevistas con los líderes de la zona rural de Usme, de lo cual, resultaron priorizados los elementos de relevancia para el modelo de OAA, que se detallan en el cuadro 2 . La repre-

Cuadro 1. Cruce multitemporal, multiespacial y multiobjetivo del modelo de ordenamiento agroambiental, 2015.

\begin{tabular}{|l|l|l|l|}
\hline \multicolumn{1}{|c|}{ UINIDAD ESPACIAL } & \multicolumn{1}{|c|}{ CORTO PLAZO } & \multicolumn{1}{c|}{ MEDIANO PLAZO } & \multicolumn{1}{c|}{ LARGO PLAZO } \\
\hline PREDIO & $\begin{array}{l}\text { Caracterización actual del predio } \\
\text { y visión del mismo a través de la } \\
\text { cartografía social con la familia } \\
\text { campesina. }\end{array}$ & $\begin{array}{l}\text { Inicio de la construcción de } \\
\text { las cercas vivas, corredores } \\
\text { biológicos y protección de los } \\
\text { nacimientos de agua. }\end{array}$ & $\begin{array}{l}\text { Implementación total de los } \\
\text { conectores para los ecosiste- } \\
\text { mas estratégicos rio Tunjuelo y } \\
\text { páramo del Sumapaz }\end{array}$ \\
\hline VEREDA & $\begin{array}{l}\text { Identificación de potencialidades, } \\
\text { oportunidades y busca solu- } \\
\text { ciones de problemas agroambi- } \\
\text { entales. }\end{array}$ & $\begin{array}{l}\text { Conformación de comités ambi- } \\
\text { entales en todas las veredas. }\end{array}$ & $\begin{array}{l}\text { Pactos de corresponsabilidad } \\
\text { agroambiental. }\end{array}$ \\
\hline ZONA SUPRAVEREDAL & $\begin{array}{l}\text { Iniciativas Comunitarias entorno } \\
\text { a la producción más limpia. }\end{array}$ & $\begin{array}{l}\text { Desarrollo de iniciativas comu- } \\
\text { nitarias. }\end{array}$ & $\begin{array}{l}\text { Gestión territorial, colaborativa y } \\
\text { participativa. }\end{array}$ \\
\hline CUENCA DEL RÍO & $\begin{array}{l}\text { Organizaciones comunitarias } \\
\text { como las JAC juntas de acue- } \\
\text { ductos veredales, ONG, CAR, } \\
\text { Instituto A.V.H., Parques Nacion- } \\
\text { ales, Min. Agricultura, Alcaldía } \\
\text { Mayor y secretarías }\end{array}$ & $\begin{array}{l}\text { Consejo de Cuenca con repre- } \\
\text { sentación del sector rural de una } \\
\text { forma activa y proactiva. CAR, } \\
\text { Instituto A.V.H., Parques Nacion- } \\
\text { ales, Min. Agricultura, Alcaldía } \\
\text { Mayor y secretarías }\end{array}$ & $\begin{array}{l}\text { Ordenamiento Agroambien- } \\
\text { tal (OAA) de la cuenca del río } \\
\text { Tunjuelo. CAR, Instituto A.V.H., } \\
\text { Parques Nacionales, Min. Agri- } \\
\text { cultura, Alcaldía Mayor y secre- } \\
\text { tarías }\end{array}$ \\
\hline
\end{tabular}


sentación gráfica del modelo que se observa en el mapa 3, se explica así: Líneas amarillas: la relación cultural creada por los pobladores de la zona entre las zonas de lagunas y el museo arqueológico. Líneas verdes: las réplicas que hay que iniciar en la zona rural, a partir de la experiencia obtenida en el Agroparque Los Soches. Líneas cafés: la relación directa entre la producción agropecuaria y el ecosistema de páramo. Línea naranja: la relación del centro poblado rural El Destino con el pueblo de Usme, donde existen flujos constantes de ida y regreso. Línea rosada: la relación del nacimiento del río Curubital y el embalse La Regadera, único santuario de fauna y flora, reconocido a nivel distrital. Flechas moradas: relación del páramo del Sumapaz con el territorio de las microcuencas de los ríos Mugroso, Chizacá y Curubital y con la zona del río Tunjuelo y del embalse de La Regadera. Franja azul: nacimiento de los ríos y principales afluentes de los embalses objeto de conservación. Franja negra: dinámicas sociales alrededor del centro poblado rural, que abarca a la mayoría de veredas de la localidad de Usme y a las veredas vecinas de Chipaque y Ciudad Bolívar.

Cuadro 2. Razones para priorizar los elementos que conforman el modelo cartográfico de OAA.

\begin{tabular}{|c|c|c|}
\hline \multirow{3}{*}{ 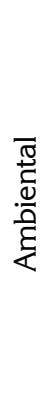 } & & $\begin{array}{l}\text { Por una parte los ríos Tunjuelo, Curubital, Chizacá y Mugroso, se proponen como los ejes hídricos del } \\
\text { modelo OAA. }\end{array}$ \\
\hline & Sistema hídrico & $\begin{array}{l}\text { Por otra, las quebradas, riachuelos y nacederos son los conectores biológicos entre los ejes principales y el } \\
\text { páramo de-Sumapaz, de las áreas de bosques alto andinas y las zonas de reserva forestal de los embalses } \\
\text { de La Regadera y Chizacá }\end{array}$ \\
\hline & $\begin{array}{l}\text { Páramo de } \\
\text { Sumapaz }\end{array}$ & $\begin{array}{l}\text { Es el ecosistema principal, ya que estructura gran parte de la ruralidad y con el planteamiento de los conec- } \\
\text { tores ecológicos para el intercambio de energías entre los ríos, embalses y relictos de bosque, se reactiva la } \\
\text { conexión entre estos espacios naturales y artificiales. }\end{array}$ \\
\hline \multirow{3}{*}{ 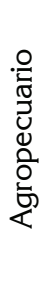 } & \multirow{2}{*}{ Predios rurales } & $\begin{array}{l}\text { Es el punto de partida de las actividades agropecuarias y ambientales de las familias campesinas de Usme } \\
\text { y donde se deben materializar las acciones, para mejorar las condiciones de vida rural. }\end{array}$ \\
\hline & & $\begin{array}{l}\text { Al precisar los límites prediales de las cercas vivas, se logrará una conexión entre el sistema hídrico y los } \\
\text { ecosistemas existentes en la ruralidad de Usme. }\end{array}$ \\
\hline & $\begin{array}{l}\text { Producción } \\
\text { Agropecuaria }\end{array}$ & $\begin{array}{l}\text { Se utiliza el } 41 \% \text { del área rural con tipología de producción campesina: agrícola, principalmente cultivos de } \\
\text { tubérculos y pecuaria, con ganado vacuno. }\end{array}$ \\
\hline \multirow{5}{*}{$\begin{array}{l}\bar{\pi} \\
\frac{\pi}{U} \\
0 \\
\text { i }\end{array}$} & Vías y caminos & Es la conexión artificial entre predios y veredas y es el punto de encuentro tradicional de la comunidad. \\
\hline & $\begin{array}{l}\text { Centro poblado } \\
\text { rural El Destino }\end{array}$ & $\begin{array}{l}\text { Es donde se ubican algunos servicios sociales, como educación, salud, cultural y deportivos; es centro de } \\
\text { intercambio dentro del modelo, tanto para la zona agroambiental del Hato como para la zona agroambi- } \\
\text { ental de La Regadera y de algunas veredas vecinas de la localidad de Cuidad Bolívar - Santa Bárbara, Las } \\
\text { Mercedes y Santa Rosa y del municipio de Chipaque -Calderitas y Fruticas. }\end{array}$ \\
\hline & Pueblo de Usme & $\begin{array}{l}\text { Es el centro urbano tradicional, en el cual, los campesinos adquieren servicios más integrales, como salud, } \\
\text { educación, mercado agrícola y ganadero, productos agro-veterinarios y se conecta con todas las demás } \\
\text { zonas agroambientales, como el centro poblado rural El Destino y, en especial, con el borde urbano-rural y } \\
\text { la malla urbana de Bogotá. }\end{array}$ \\
\hline & $\begin{array}{l}\text { Agroparque Los } \\
\quad \text { Soches }\end{array}$ & $\begin{array}{l}\text { Es un hito para el campesinado nacional, tiene un área de } 328 \text { ha y está previsto para el desarrollo de } \\
\text { turismo rural, producción más limpia, mantenimiento de áreas de reserva y construcción de procesos de } \\
\text { producción sostenibles, en general es donde se propone otra forma alternativa a la cuidad. }\end{array}$ \\
\hline & $\begin{array}{l}\text { Museo } \\
\text { arqueológico de } \\
\text { Usme }\end{array}$ & $\begin{array}{l}\text { Se ubica en la vereda La Requilina, donde se detuvo un proceso urbanístico ante el hallazgo de un gran } \\
\text { cementerio indígena, con más de } 2.000 \text { años de antigüedad y más de } 1.500 \text { tumbas. }\end{array}$ \\
\hline
\end{tabular}




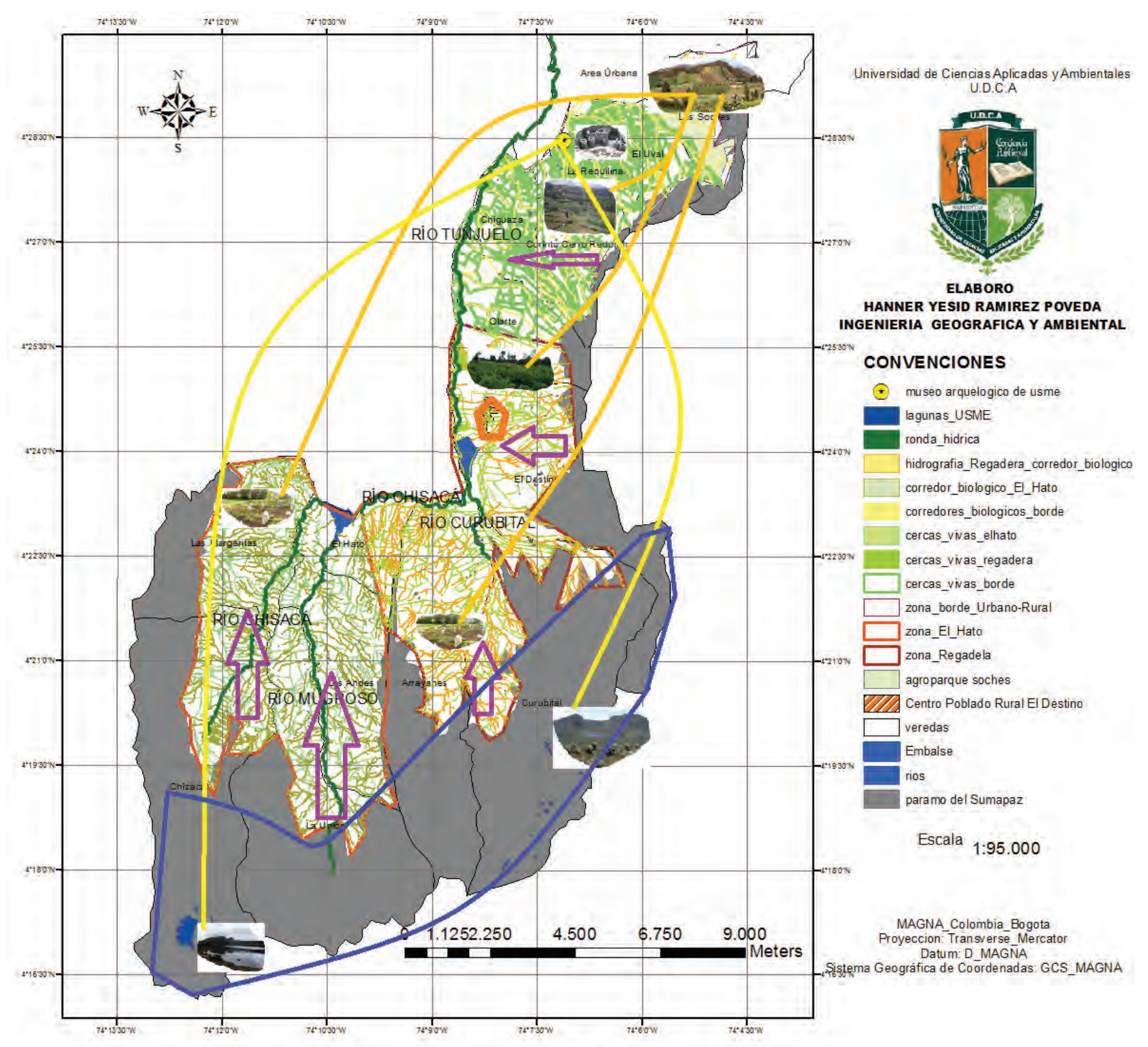

Mapa 3. Representación cartográfica del modelo de ordenamiento agroambiental.

Flujos relacionados con el centro poblado rural El Destino

Entrada interveredal: flujo directo entre la población de las veredas Chizacá, La Unión, Los Andes, Las Margaritas, El Hato, Los Arrayanes, Curubital, Olarte y El Destino. Entrada interlocal: relación directa con la población de las veredas de Cuidad Bolívar (Santa Bárbara, Santa Rosa y Las Mercedes). Entrada intermunicipal: existe una relación específicamente con dos veredas del municipio de Chipaque: Calderitas, Fru- ticas. Entrada y salida local: relación directa entre el pueblo de Usme y el centro poblado rural El Destino.

Se realiza, además, un énfasis especial en dos tipos de conectores biológicos (Figura 1): Corredores biológicos para restaurar y proteger las fuentes hídricas y conectar los ríos con el páramo y con las zonas de los embalses; cercas vivas, ubicadas en los límites prediales y en los caminos o vías, con siembra de árboles nativos, propios del ecosistema bosque alto andino, como arrayan (Myrcianthes leucoxyla), aliso 
(Alnus glutinosa), sauco (Sambacus nigra), roble o chaque (Quercus robur), arbolocos (Montanoa cuadrangulares), mortiño (Hesperomeles goudotiana), uva caimarona (Pourouma cecropiifolia), encenillos (Weinmannia tomentosa) y duraznillos (Abatia parviflora).

Los resultados de este ejercicio están acorde con Delgadillo Macías \& Torres Torres (2010), para quienes cada vez cobra mayor importancia el enfoque territorial del desarrollo rural, por la integralidad de factores y la lógica de planeación orientada al territorio, con puntos de interacción entre los sistemas humanos y los sistemas ambientales y también con Méndez Sastoque (2012), para quien se convierte en una urgencia, debido a que las apreciaciones positivas del modo de ser campesino son parte de una idiosincrasia que entiende mejor que cualquier ciudadano, los valores de su territorio, los valores anhelados por todos y que hoy son casi inexistentes en el entorno urbano.

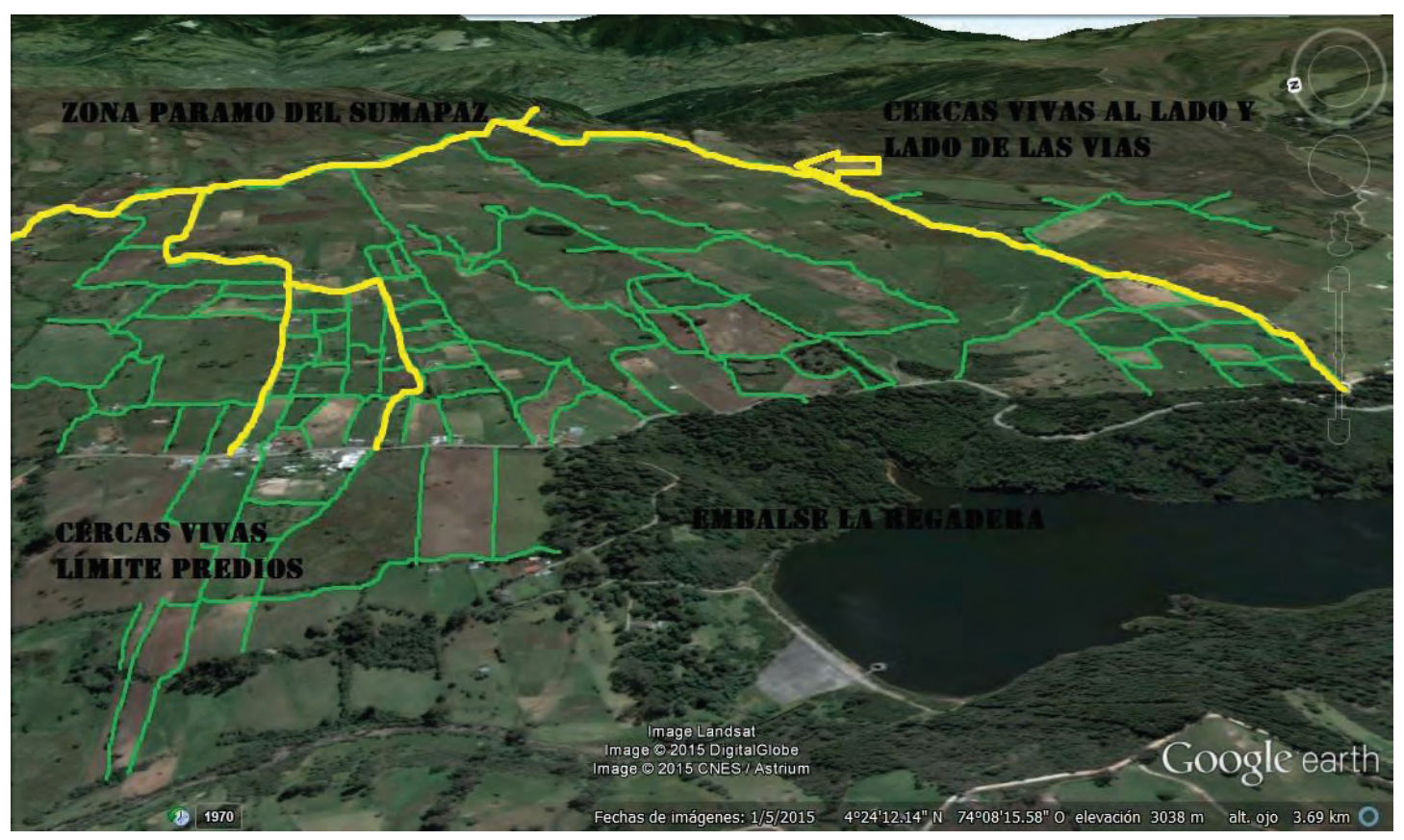

Figura 1. Diseño de la conectividad principal y secundaria del modelo, 2015.

En teoría, en Colombia, el MADR (2013) ha creado, mediante Decreto 1986, un sistema de coordinación para la formulación, la ejecución y el seguimiento de las políticas, los programas, los planes y los proyectos necesarios para el cumplimiento del Pacto Nacional por el Agro y el Desarrollo Rural. Específicamente en Bogotá, se ha creado, desde el 2010, el Plan de Gestión para el Desarrollo Rural Sostenible, como un instrumento de gestión y de planeación, que orienta las acciones o los proyectos prioritarios de los futuros Planes de Desarrollo Distrital y Planes de Desarrollo Local, articulando las instituciones del Distrito sobre la ruralidad de Bogotá; en su interior, se plantea un programa colectivo para la conservación del territorio rural (Alcaldía Mayor de Bogotá, 2009). Asunto que se complementa con la creación del Consejo Consultivo de Ambiente que, mediante mesas de trabajo, pretende discutir diferentes estrategias e intervenciones para la implementación de políticas ambientales o instrumentos de planeación ambiental en el Distrito (Alcaldía Mayor de Bogotá, 2014).
En otras palabras, existen varias intenciones bien planeadas y cada vez más integradas, pero es en el seno del territorio rural, donde se construyen los modelos y se ejecutan las acciones necesarias para que se haga realidad, pues como lo expresa Sepúlveda et al. (2003), el enfoque territorial del desarrollo rural es apenas el estadio lógico de un largo proceso de aproximaciones a un nuevo paradigma de desarrollo. En el enfoque territorial, la unidad de observación, análisis e intervención se estructura a partir de la integración de los elementos espacio-temporales. Este es el caso de Costa Rica, donde se viene promoviendo que la comunidad organizada define los problemas que más le afectan, propone soluciones y el Estado apoya tales iniciativas (Sepúlveda, 2008).

En ejemplos a seguir, como es el caso de Brasil, la discusión sobre el desarrollo rural se conecta también al debate más general sobre los procesos de cambio social, que deberían favorecer la mejora de la calidad de vida, pues se trata de un proceso de generación de la autonomía y de la 
construcción de un proyecto colectivo, como única forma posible para darle sentido a la sociedad (Schneider \& Peyré, 2006), lo cual, se resalta con la posición de Portilla (2003), para quien el desarrollo rural es el resultado de la acción de múltiples grupos y de actores sociales y, desde la óptica del desarrollo territorial, los actores sociales se reconocen por su capacidad colectiva para asumir la función de planificación y de gestión ascendente del desarrollo, siguiendo los principios de cooperación y de responsabilidad compartida. El enfoque territorial del desarrollo rural rescata, precisamente, esa noción de integralidad, que permite repensar los papeles reales y potenciales, que los distintos grupos de población y de actores sociales asumen en la construcción de modelos sostenibles de desarrollo territorial.

Se concluye, entonces, que en Colombia, en el tema agroambiental, se registran pocas experiencias, ya que no se planifican unas políticas, ni planes, ni proyectos que integren el tema agropecuario y ambiental en conjunto con los campesinos, por lo que hace falta un instrumento que reglamente el ordenamiento agroambiental, de manera que se pueda incluir no solo en la planeación, sino en la gestión territorial. Pero ello no tendría sentido, si no se realiza conjuntamente con los habitantes del territorio rural, quienes, como en el caso de esta propuesta para modelar el OAA, tienen todos los elementos para su diseño.

Agradecimiento: Los autores agradecen a la U.D.C.A por financiar el proyecto de investigación "Gestión Ambiental Territorial en Bogotá", que dio origen a este manuscrito. Conflicto de Intereses: El manuscrito fue preparado y revisado con la participación de todos los autores, quienes declaramos que no existe conflicto de intereses que ponga en riesgo la validez de los resultados presentados.

\section{BIBLIOGRAFÍA}

1. ALCALDÍA MAYOR DE BOGOTÁ. 2014. Decreto 81 de 2014. Por medio del cual se crea y conforma el Consejo Consultivo de Ambiente. 3p.

2. ALCALDÍA MAYOR DE BOGOTÁ. 2009. Plan de Gestión para el Desarrollo Rural Sostenible, del Distrito de Bogotá. Secretaria Distrital de Ambiente. Secretaria Distrital de Planeación. Colombia. 170p.

3. AYALA ORTIZ, D.A.; SCHWENTESIUS, R.; GÓMEZ C., M.A. 2008. La ecocondicionalidad como instrumento de política agrícola para el desarrollo sustentable en México. Gestión y Política Pública. 17(2):315-353.

4. BUSTAMANTE, C. 2013. Fortalecimiento de las políticas agro-ambientales en países de América Latina y el Caribe a través del dialogo e intercambio de ex- periencias nacionales, Caso Colombia. FAO. 240p. Disponible desde internet en: http://www.fao.org/3/aas223s.pdf (con acceso 19/08/2015).

5. CARVAJAL SÁNCHEZ, N.I. 2011. Enfoque ascendente e enfoque descendente do ordenamento territorial na Colômbia. Cuadernos de geografía. Rev. Col. Geografía. 20(1):21-28.

6. DELGADILLO MACÍAS, J.; TORRES TORRES, F. 2010. La gestión territorial como instrumento para el desarrollo rural. Estudios Agrarios. 55p.

7. GARAY SALAMANCA., L.J.; BAILEY, R.; FORERO A., J.; BARBERI GÓMEZ, F.; RAMÍREZ G., C.; SUÁREZ V., D.; GÓMEZ M., R.; CASTRO F., Y.; ÁLVAREZ Z., J.; ROLDAN O., R.; SÁNCHEZ B., E.; MACHADO C., A.; SALGADO A, C.; NARANJO, S.; PERRY, S. 2013. Reflexiones sobre la ruralidad y el territorio en Colombia. Problemáticas y retos actuales. OXFAM, Cooperación Alemana GIZ, Comisión de Seguimiento a la Política Pública sobre el Desplazamiento Forzado, Embajada del Reino los Países Bajos y Pontificia Universidad Javeriana. 447p.

8. FAO. 2014. Políticas agroambientales en América Latina y el Caribe Análisis de casos de Brasil, Chile, Colombia, México y Nicaragua. 74p.

9. MATEUS MORENO., L.; ROJAS SALAZAR., L. 2013. Fortalecimiento de las políticas agro-ambientales en países de América Latina y el Caribe a través del dialogo e intercambio de experiencias nacionales, Caso Colombia. FAO. 240p. Disponible desde internet en: http://www.fao.org/3/a-as223s.pdf (con acceso 25/10/2015).

10. MERA CHARÁ, E.M.; GALINDO LUCAS, A. 2005. Geopolítica e impacto agroambiental en Colombia, el avance del ecosistema humano. Historia Actual Online -HAOL-, 1:67-73 España. Disponible desde internet en: file:///C:/Users/udca_pc/Downloads/ Dialnet-GeopoliticaEImpactoAgroambientalEnColombia-876581.pdf (con acceso 20/08/2015).

11. MÉNDEZ SASTOQUE, M.J. 2012. El neorruralismo como práctica configurante de dinámicas sociales alternativas: un estudio de caso. Rev. Luna Azul. 34:113-131.

12. MINISTERIO DE AGRICULTURA Y DESARROLLO RURAL -MADR-. 2013. Decreto 1987. Por el cual se organiza el sistema de coordinación de actividades públicas, privadas y de inclusión social para el cum- 
plimiento del Pacto Nacional por el Agro y el Desarrollo Rural. Colombia. 5p.

13. PORTILLA, M. 2003. Actores sociales en el desarrollo rural territorial. Instituto Interamericano de Cooperación para la Agricultura. SINOPSIS No 8. 8p.

14. POSADA, A. 2009. Intereses ambientales: reflexiones sobre la aplicación de lo difuso. Rev. Ingenierías. 8(14):11-20.

15. POSADA, A. 2012. Análisis de intereses ambientales mediante lógica difusa: caso reserva forestal regional del norte de Bogotá-Colombia. Rev. U.D.C.A Act. \& Div. Cient. 15(2):437-498.

16. POSADA, A. 2014. De la planeación a la gestión ambiental colectiva: posibilidades en Bogotá-Colombia. Rev. U.D.C.A Act \& Div. Cient. 17(1):257-264.

17. REPÚBLICA DE COLOMBIA. 1974. Decreto Ley 2811. Código Nacional de Recursos Naturales Renovables y de Protección al Medio Ambiente. Diario oficial No. 34243.

18. SEPÚLVEDA, S.; RODRÍGUEZ, A.; ECHEVERRI, R.; PORTILLA, M. 2003. El enfoque territorial de desarrollo. IICA. Costa Rica. 180p.
19. SEPÚLVEDA, S. 2008. Gestión del desarrollo sostenible en territorios rurales. IICA. Costa Rica. 416p.

20. SCHNEIDER, S.; PEYRÉ T., I. 2006. Desarrollo Rural. Organizaciones, Instituciones y Territorio. Ed. Ciccus. Buenos Aires, p.71-102.

21. UNIVERSIDAD DEL ROSARIO. 2012. Tres Valles: el territorio de la economía. Una estrategia de ordenamiento económico-territorial para los valles de Aburrá, Occidente Cercano y San Nicolás en Antioquia. CEPEC. Comisión tripartita. 412 p.

22. TORRES LIMA, P.; CRUZ CASTILLO, J.G.; ACOSTA BARRADAS, R. 2011. Vulnerabilidad agroambiental frente al cambio climático. Agendas de adaptación y sistemas institucionales. Política y Cultura de México. 36:205-232.

Recibido: Agosto 23 de 2015

Aceptado: Octubre 30 de 2015

\section{Cómo citar:}

Posada Arrubla, A.; Ramírez Poveda, H.Y. 2015. Aproximación a la gestión territorial rural desde un modelo de ordenamiento agroambiental. Rev. U.D.C.A Act. \& Div. Cient. 18(2): 513-523. 